\title{
Conditions Associated with Intrauterine Fetal Demise (IUFD) in Pregnant Women at King Abdulaziz University (KAUH). A Five-Year Experience
}

\author{
Abdullah M. Kafy, Ayman Oraif* \\ King Abdulaziz University, Jeddah, KSA \\ Email: *ayman_oraif@yahoo.com
}

How to cite this paper: Kafy, A.M. and Oraif, A. (2017) Conditions Associated with Intrauterine Fetal Demise (IUFD) in Pregnant Women at King Abdulaziz University (KAUH). A Five-Year Experience. Open Journal of Obstetrics and Gynecology, 7, 1262-1270. https://doi.org/10.4236/ojog.2017.713129

Received: September 24, 2017 Accepted: December 16, 2017 Published: December 19, 2017

Copyright ( 92017 by authors and Scientific Research Publishing Inc. This work is licensed under the Creative Commons Attribution International License (CC BY 4.0).

http://creativecommons.org/licenses/by/4.0/ (c) (i) Open Access

\begin{abstract}
Background: Intrauterine fetal demise is the death of the fetus after twenty week of gestation but before the onset of labor. In more than $50 \%$ of cases, the etiology of antepartum fetal death is not known or cannot be determined. Several factors attributed to the risk of IUFD. This study aimed to determine the incidence of IUFD, as well as associated conditions. Method: This retrospective study enrolled all pregnant women who attending at KAUH between 2011 and 2015. Results: During the last five years 248 verified IUFD cases were reported, the mean age was 30.59. Saudi nationality represented by $27 \%$. PET was represented $17.7 \%$ and congenital malformation was represented by $7.3 \%$ as risk factors. Regarding the mode of delivery SVD was $58.9 \%$ followed by CS 28.6. Conclusion: Stillbirth is an unfavorable event, there are several factors (maternal, fetal \& placenta) associated with IUFD. Providing good level of antenatal care helped in reducing IUFD incidence.
\end{abstract}

\section{Keywords}

High Risk Pregnancy, Intrauterine Fetal Death, Conditions

\section{Introduction}

One of the important predictor about country's development is the mortality proportion among children, where most of these deaths occurred during the period between $22^{\text {th }}$ week of pregnancy and the first month of life [1] [2], one of this situation is Intrauterine fetal demise, which is defined as the death of the fetus after twenty week of gestation but before the onset of labor, with birth weight > 
$500 \mathrm{gm}[3]$.

In more than $50 \%$ of cases, the etiology of antepartum fetal death is not known or cannot be determined [3], where several maternal, placental or fetal factors attributed to the risk of IUFD, such as (pregnancy hypertension, diabetes, high parity, advanced maternal age, abruption placenta, congenital anomalies, intrauterine growth retardation, severe fetal growth restriction (FGR) or cord accident) [4] [5] [6]. In addition, several studies results showed that unexplained fetal deaths happened even with women who had consistent antenatal care [6] [7].

Several studies reported 3 million cases/year of IUFD around the world where almost third quarter (70\%) lied in the developing countries in Asia and sub Saharan Africa together due to several reasons such as: lack of prenatal care, shortage of health care facility [3] [4] [8] (Figures 1-4).

Over the last five decades there was huge positive changes in the model of antenatal care (ANC), which become clear that early ANC has a big influence on the maternal and fetal health, due to the ability of diagnosis health problems earlier than before, teaching women the labor signs and delivery difficulties, referring to competent Obstetrician-Gynecologist, which help in decreasing and preventing stillbirths cases [8] [9] [10].

This study aimed to determine the incidence of IUFD, as well as associated conditions among pregnant women who delivered at King Abdualazi University

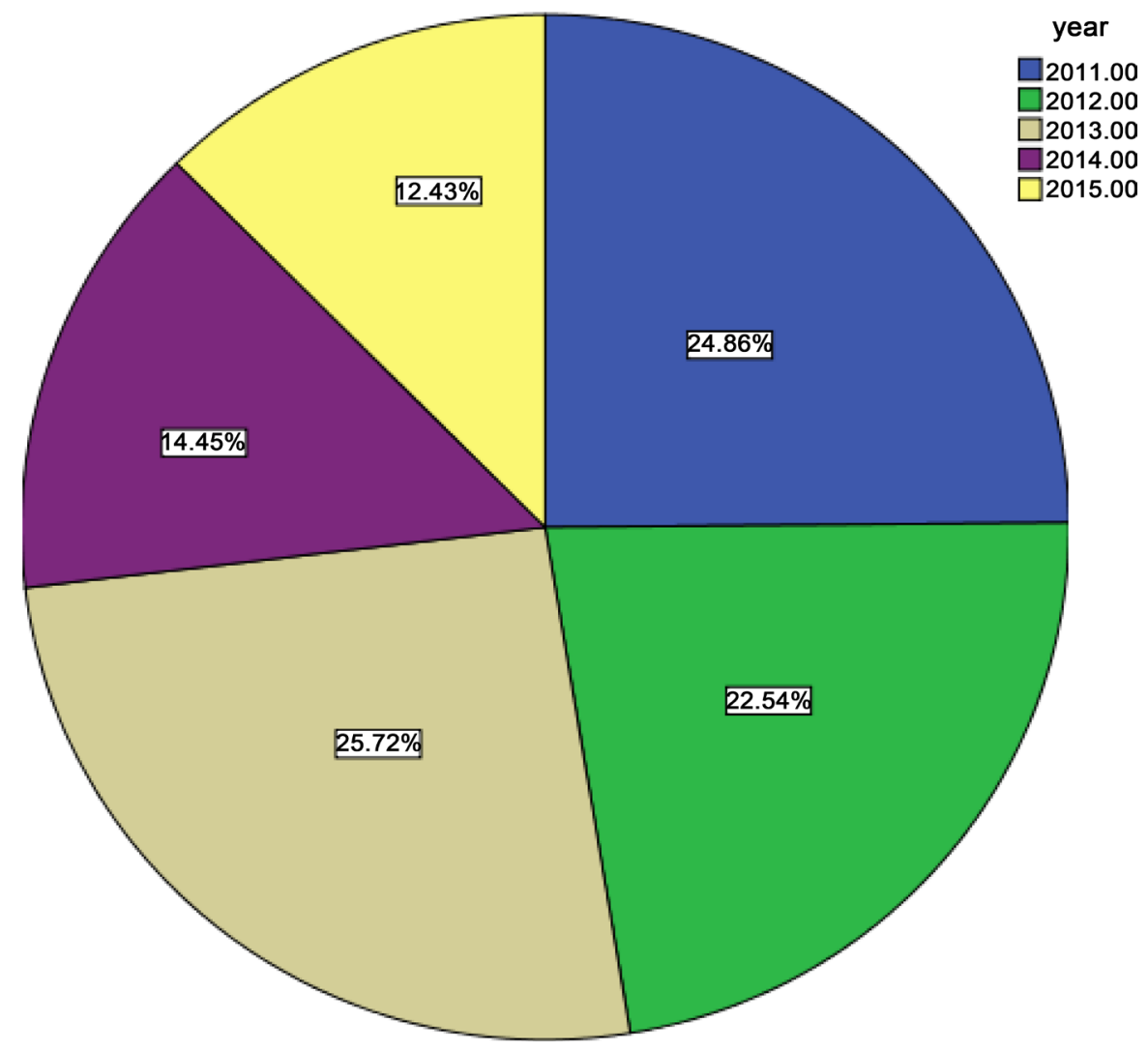

Figure 1. Distribution of the IUFD according to years. 


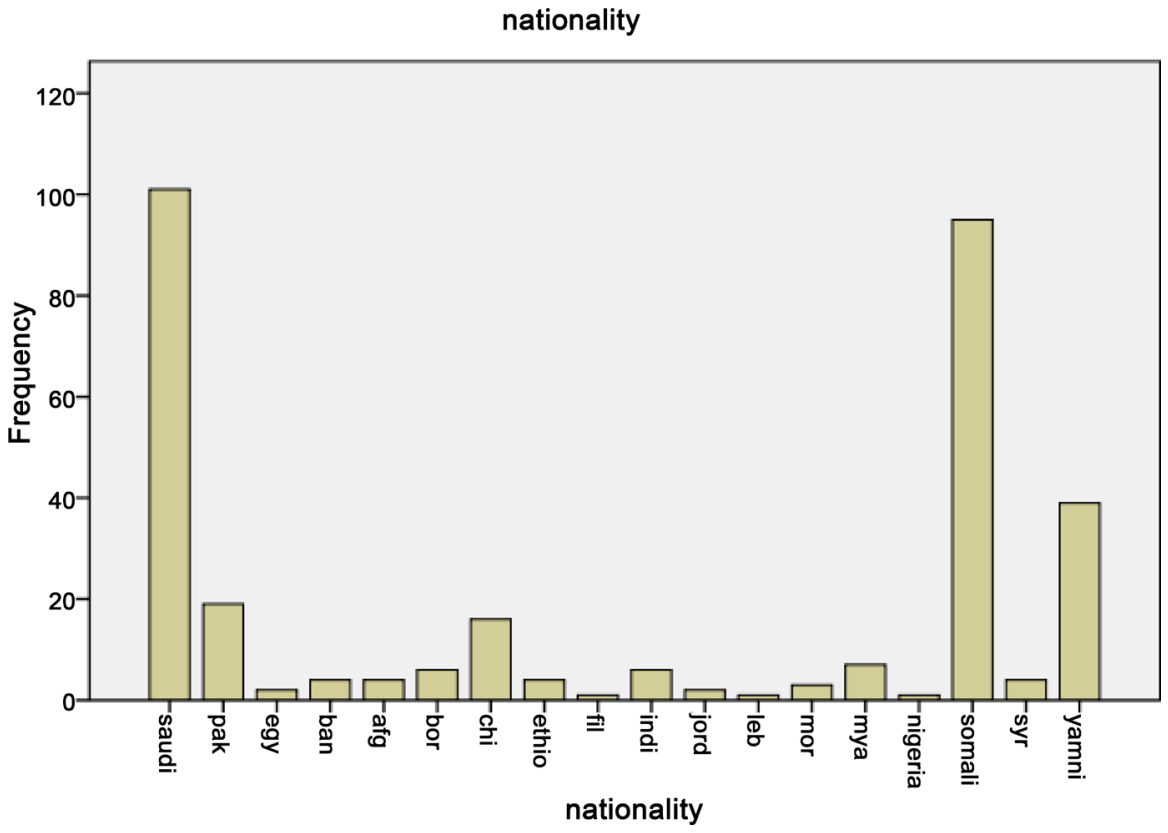

Figure 2. Nationality of the studied verified IUFD.

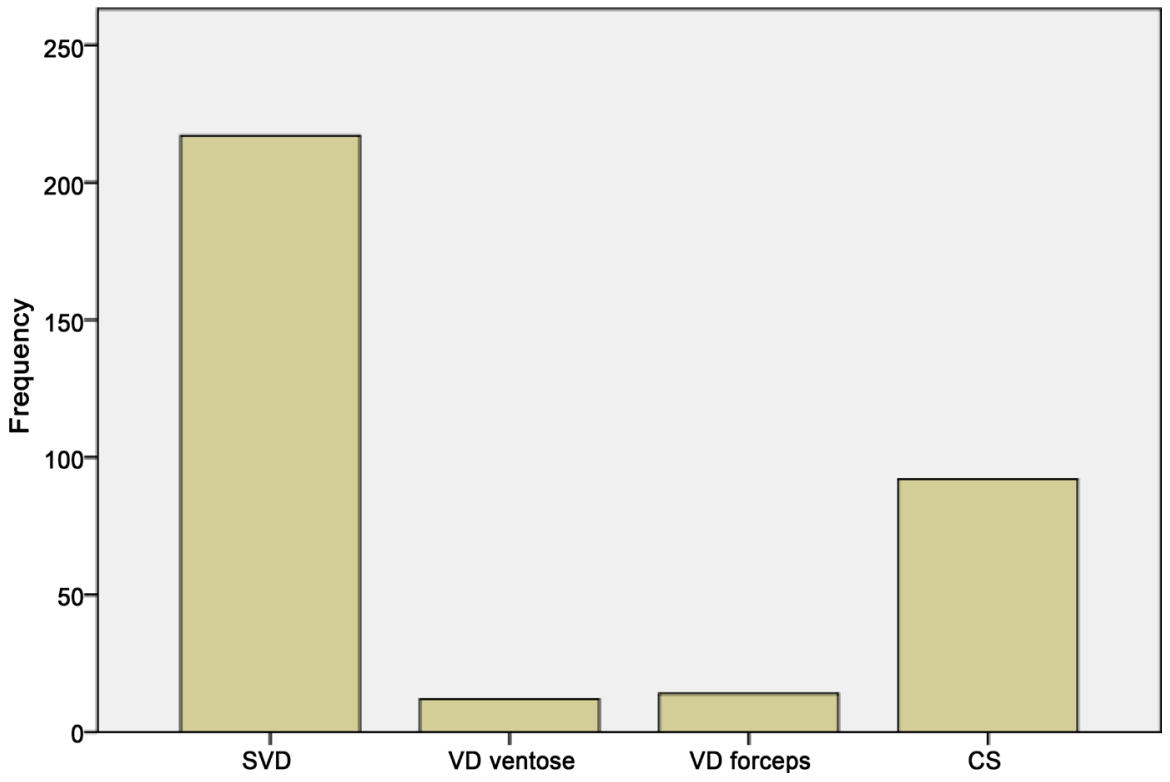

Figure 3. Mode of delivery of verified IUFD.

Hospital in Jeddah, Saudi Arabia.

\section{Subject and Method}

This retrospective study was enrolled all pregnant women who attending at KAUH between 2011 and 2015. Inclusion criteria include pregnant women in the labor and delivery room, admitted to the hospital over 5-years duration. Data were collected from medical log book. Factors that may have contributed to the occurrence of IUFD were explored focusing on age, gestational age, parity, BMI, mode of delivery. 


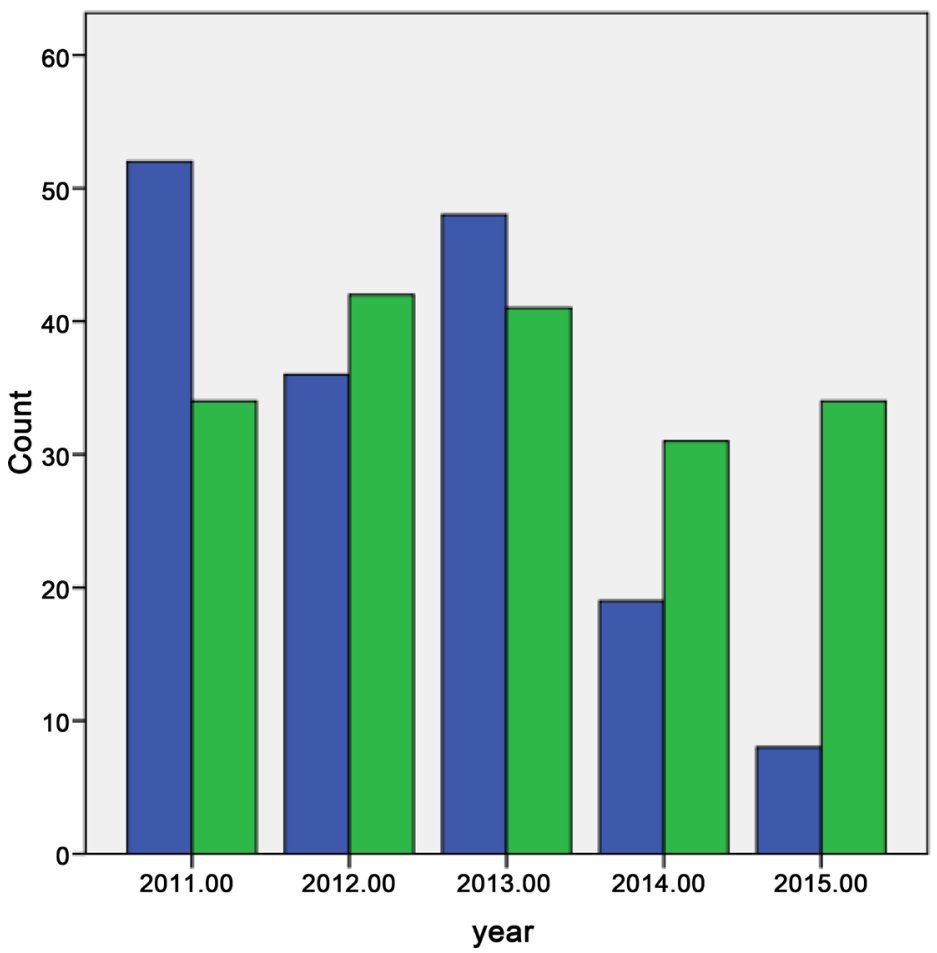

Figure 4. Relation between booking status and year of the study for verified IUFD.

\section{Statistical Analysis}

The collected data were analyzed using the SPSS statistical software package, version 20. Parametric data are expressed as mean and standard deviations (minimum and maximum) and non-parametric data are expressed as number (percentage). Chi-square was used as a test of significance for comparison of qualitative data Significance was considered at $\mathrm{p}$ value less than 0.05 .

\section{Results}

Table 1 showed total number and percentage of IUFD and verified IUFD. The incidence rates of verified IUFD were 1.3. 1.1, 1.5, 0.7 and 0.9 respectively from 2011 to 2015. No significant difference was detected between the studied years regarding verified IUFD.

Table 2 showed Age of mother, Parity and gestational age of the studied confirmed IUFD. The mean age was 30.59 year, the median parity was 2 and the gestational age was 32.22 weeks

Table 3 showed nationality of the studied confirmed IUFD. Saudi nationality represented by $27 \%$. Somali represented by $26.6 \%$ and Yemen represented by $11.4 \%$.

Table 4 Showed Risk factor of the studied confirmed IUFD, PET was represent 17.7, placental 7.3\%, and congenital anomalies represent 5.6\%.

Table 5 showed mode of delivery of confirmed IUFD. The commonest mode of delivery was SVD $58.9 \%$ followed by CS $28.6 \%$.

Table 6 Relation between booking status and year of the study for confirmed 
IUFD. There were low significance booking rate in 2014 and 2015 than other years.

Table 1. Incidence of Intra uterine fetal death according to year of the study.

\begin{tabular}{cccc}
\hline Years & Total number of year & Intra-uterine foetal death (IUFD) & Verified IUFD \\
\hline 2011 & 4831 & $86(1.7)$ & $64(1.3)$ \\
2012 & 5385 & $78(1.4)$ & $58(1.1)$ \\
2013 & 4276 & $89(2)$ & $661.5)$ \\
2014 & 3710 & $50(1.3)$ & $27(0.07)$ \\
2015 & 3637 & $43(1.1)$ & $33(0.09)$ \\
Total & & 248 & 346 \\
\hline
\end{tabular}

Table 2. Age of mother, parity and gestational age of the studied confirmed IUFD.

\begin{tabular}{ccccc}
\hline Variables & Mean & Median & SD & Min-Maximum \\
\hline Age & 26.59 & 26 & 6.75 & $(17-43)$ \\
parity & 2.5 & 2 & 2.58 & $(2-14)$ \\
Gestational age & 32.22 & 33 & 6.98 & $(20-46)$ \\
\hline
\end{tabular}

Table 3. Nationality of the studied verified IUFD.

\begin{tabular}{|c|c|c|}
\hline Nationality & IUFD Number & Percentage \\
\hline Saudi & 67 & (27) \\
\hline Pak & 15 & (6) \\
\hline Egypt & 1 & $(0.4)$ \\
\hline Bang & 3 & $(1.2)$ \\
\hline Afg & 4 & (1.6) \\
\hline Borm & 3 & $(1.2)$ \\
\hline Chinese & 15 & (27) \\
\hline Ethio & 3 & (6) \\
\hline Phipino & 1 & $(0.34)$ \\
\hline India & 4 & (1.6) \\
\hline Jordan & 2 & $(0.8)$ \\
\hline Lebanon & 1 & $(0.4)$ \\
\hline Moro & 1 & $(0.4)$ \\
\hline Malaysian & 6 & $(2.4)$ \\
\hline Somali & 66 & $(26.6)$ \\
\hline Syria & 4 & $(1.6)$ \\
\hline Yemen & 28 & $(11.3)$ \\
\hline Missing & 24 & $(9.7)$ \\
\hline Total & 248 & \\
\hline
\end{tabular}


Table 4. Risk factor of the studied confirmed IUFD.

\begin{tabular}{ccc}
\hline Risk factors & No & $\%$ \\
\hline PET & 44 & $(17.7)$ \\
Twins & 12 & $(4.8)$ \\
Placental & 18 & $(7.3)$ \\
Congenital & 14 & $(5.6)$ \\
DM & 17 & $(6.9)$ \\
Cord prolapsed & 3 & $(1.2)$ \\
Chorioamnionitis & 2 & $(0.8)$ \\
PIH & 4 & $(1.6)$ \\
Previous IUFD & 8 & $(3.2)$ \\
Previous CS & 14 & $(5.6)$ \\
Hydrops fetalis & 4 & $(1.6)$ \\
Missing & 108 & $(43.5)$ \\
Total & 248 & \\
\hline
\end{tabular}

Table 5. Mode of delivery of verified IUFD.

\begin{tabular}{ccc}
\hline Mode of delivery & No & $\%$ \\
\hline SVD & 146 & $(58.9)$ \\
VD ventose & 12 & $(4.8)$ \\
VD forceps & 12 & $4.8)($ \\
CS & 71 & $(28.6)$ \\
Missing & 7 & $(2.8)$ \\
Total & 248 & \\
\hline
\end{tabular}

Table 6. Relation between booking status and year of the study for verified IUFD.

\begin{tabular}{lccc}
\hline & Booked N \% & Unbooked N \% & Test of sig \\
\hline 2011 & $36(31)$ & $28(21.4)$ & \\
2012 & $28(24.1)$ & $30(22.9)$ & Chi-square test \\
2013 & $36(31)$ & $30(22.9)$ & $\mathrm{P}=0.005^{* *}$ \\
2014 & $10(8.6)$ & $17(13)$ & \\
2015 & $6(5.2)$ & $26(19.8)$ & \\
\hline
\end{tabular}

\section{Discussion}

The rate of IUFD cases are different between countries, cities, even differ from year to year, this variance due to the fact that there are several factors such as antenatal care service quality, the argument between researchers in determining gestational age and weight of the fetus in the definition of IUFD [4] [7]. Several studies were carried out to define the risk factors caused IUFD, these factors di- 
vided to three main categories maternal, placental or fetal factors such as poor antenatal care, preterm delivery, low birth weight, Congenital, maternal age \& chronic illness (GDM \& hypertension) [7] [11].

As regards to maternal factors associated with fetus death, several studies addressed the relation between maternal age and IUFD, where childbearing women younger than 20 and older than 40 years are more likely to have stillbirth than women in group age 24 - 35 years and the problem become more obvious in women aged $\geq 40$ years [12] [13]. In addition to that the relation between maternal age and both gestational age and birth weight are confirmed, where women older than 40 years have more chance to performed C/S and have macrocosmic neonate [13] [14]. The results of the current study consistent with previous studies and showed that the mean age score was $30.6 \pm 6.7$.

Placental complications, PET, and umbilical cord \& are important risk factors associated with IUFD, where $2.7 \%$ of obstructed fetal blood flow death cases are linked to nuchal cord in $23 \%$ of the cases and $1 \%$ of true umbilical knots, where there is need for pathological anatomy examination to detect if knot or nuchal cord are the real cause of death, where it could induce rupture or inflammation and cause Placental abruption which is fetal in $0.12 \%$ of the cases and presents as bleeding and abdominal pain [14] [15].

Congenital anomalies is the biggest risk factor cause perinatal death fetuses in the current study 14 cases (5.6\%) had congenital anomalies [16].

Several studies addressed the ability of preventing and avoiding the majority of the previous risk factors by provide good level of antenatal care (ANC), where good level of antenatal care help in controlling a lot of factors (blood sugar level, blood pressure), earlier diagnosis of congenital anomalies, prescribe folic Acid, which provide a good chance to early referral to good center for C/S section in high risk cases [7] [9]. The authors in Ethiopia study recorded that the variety in ANC care between urban \& rural areas induced difference rate of IUFD cases [2]. In another study the authors reported that $38 \%$ of the IUGR cases didn't have any antenatal care [17]. Also in South African study 2015 the authors stated that managing maternal health condition by intrapartum care during the three semesters had a good effect on reducing IUFD cases [18]. All the studies highlighted the following statement, when there is previous unexplained IUFD there is a great need of intensive ANC to reduce stillbirth incidence or at least provide the parents with explanation of the cause of fetus death [7] [19]. The result of the current study is consistent with previous study where the rate of IUFD was less among booked mother than un-booked mother.

\section{Conclusion}

In conclusion, stillbirth is a sadness event for both the parents and the obstetrician. Even with the high improvement in the quality of care among the health field still there is significant rate of IUFD cases, due to several factors (maternal, fetal \& placenta). Providing good level of antenatal care helped in reducing IUFD inci- 
dence. Further studies need to be carried out to increase the information about this sadness event in order to develop more suitable and effective health strategies to decrease and prevent IUFD. Also there is need for more educational program to raise the level of awareness about the importance of antenatal care and its impact on reducing fetus death rate among the community.

\section{References}

[1] Koshida, S., Ono, T., Tsuji, S., Murakami, T. and Takahashi, K. (2015) Recommendations for Preventing Stillbirth: A Regional Population-Based Study in Japan during 2007-2011. Tohoku Journal of Experimental Medicine, 235, 145-149. https://doi.org/10.1620/tjem.235.145

[2] Gizaw, M., Molla, M. and Mekonnen, W. (2014) Trends and Risk Factors for Neonatal Mortality in Butajira District, South Central Ethiopia, (1987-2008): A Prospective Cohort Study. BMC Pregnancy Childbirth, 11, 64.

[3] Silver, R.M., Varner, M.W., Reddy, U., Goldenberg, R., Pinar, H., Conway, D., Bukowski, R., Carpenter, M., Hogue, C., Willinger, M., Dudley, D., Saade, G. and Stoll, B. (2007) Work-Up of Stillbirth: A Review of the Evidence. American Journal of Obstetrics and Gynecology, 196, 433-444. https://doi.org/10.1016/j.ajog.2006.11.041

[4] Choudhary, A. and Vineeta Gupta, V. (2014) Epidemiology of Intrauterine Fetal Deaths: A Study in Tertiary Referral Centre in Uttarakhand IOSR. Journal of Dental and Medical Sciences, 13, 3-6. https://doi.org/10.9790/0853-13320306

[5] Huang, D.Y., Usher, R.H., Kramer, M.S., Yang, H., Morin, L. and Fretts, R.C. (2000) Determinants of Unexplained Ante-Partum Fetal Death. Journal of Obstetrics and Gynaecology, 95, 215-221.

[6] Singh, N., Pandey, K., Gupta, N., Arya, A.K., Pratap, C. and Naik, R. (2013) A Retrospective Study of 296 Cases of Intra Uterine Fetal Deaths at a Tertiary Care Center in Kanpur, India. International Journal of Reproduction, Contraception, Obstetrics and Gynecology, 2, 141-146. https://doi.org/10.5455/2320-1770.ijrcog20130606

[7] Lamia, A., Shaaban, L.A., Al-Saleh, R.A., Alwafi, B.M. and Al-Raddad, R.M. (2006) Associated Risk Factors with Ante-Partum Intra-Uterine Fetal Death. Saudi Medical Journal, 27, 76-79.

[8] Sharma, S., Sidhu, H. and Kaur, S. (2016) Analytical Study of Intrauterine Fetal Death Cases and Associated Maternal Conditions. International Journal of Applied and Basic Medical Research, 6, 11-13. https://doi.org/10.4103/2229-516X.173986

[9] Roxanne Beauclair, R., Petro, G. and Myer, L. (2014) The Association between Timing of Initiation of Antenatal Care and Stillbirths: A Retrospective Cohort Study of Pregnant Women in Cape Town, South Africa. BMC Pregnancy and Childbirth, 14, 204. https://doi.org/10.1186/1471-2393-14-204

[10] Yakoob, M.Y., Lawn, J.E., Darmstadt, G.L. and Bhutta, Z.A. (2010) Stillbirths. Epidemiology, Evidence, and Priorities for Action. Seminars in Perinatology, 34, 387-394. https://doi.org/10.1053/j.semperi.2010.09.010

[11] Berhan, Y. and Berhan, A. (2014) A Meta-Analysis of Selected Maternal and Fetal Factors for Perinatal Mortality. Ethiopian Journal of Health Sciences, 24, 55-68. https://doi.org/10.4314/ejhs.v24i0.6S

[12] Mutz-Dehbalaie, I., Scheier, M., Jerabek-Klestil, S., Brantner, C., Windbichler, G.H., Leitner, H., Egle, D., Ramoni, A. and Oberaigner, W. (2014) Perinatal Mortality and Advanced Maternal age. Gynecologic and Obstetric Investigation, 77, 50-57. 
https://doi.org/10.1159/000357168

[13] Weng, Y.H., Yang, C.Y. and Chiu, Y.W. (2014) Risk Assessment of Adverse Birth Outcomes in Relation to Maternal Age. PLOS ONE, 9, e114843.

https://doi.org/10.1371/journal.pone.0114843

[14] Siddiqui, F. and Lucy Kean Intrauterine, K. (2008) Intrauterine Fetal Death. Obstetrics, Gynecology and Reproductive Medicine, 19, 1.

[15] Kidron, D., Bernheim, J. and Aviram, R. (2009) Placental Findings Contributing to Fetal Death, a Study of 120 Stillbirths between 23 and 40 Weeks Gestation. Placenta, 30, 700-704. https://doi.org/10.1016/j.placenta.2009.05.009

[16] Unterscheider, J., O’Donoghue, K., Daly, S., Michael, P., Geary, M., Kennelly, M.M., et al. (2014) Fetal Growth Restriction and the Risk of Perinatal Mortality-Case Studies from the Multicenter PORTO Study. BMC Pregnancy Childbirth, 14, 63. https://doi.org/10.1186/1471-2393-14-63

[17] Gebhardt, S. and Oberholzer, L. (2015) Elective Delivery at Term after a Previous Unexplained Intra-Uterine Fetal Death: Audit of Delivery Outcome at Tygerberg Hospital, South Africa. PLoS ONE, 10, e0130254. https://doi.org/10.1371/journal.pone.0130254

[18] Allanson, E.R., Muller, M. and Pattinson, R.C. (2015) Causes of Perinatal Mortality and Associated Maternal Complications in a South African Province: Challenges in Predicting Poor Outcomes. BMC Pregnancy Childbirth, 15, 37. https://doi.org/10.1186/s12884-015-0472-9

[19] Mohamed, M.S., Zahran, K.M., Mohamed, H.S., Galal, H. and Mustafa, A.M. (2015) Pattern of Glucose Intolerance among Pregnant Women with Unexplained IUFD. Middle East Fertility Society Journal, 20, 43-47. https://doi.org/10.1016/j.mefs.2014.04.004 